\title{
Sonographic evaluation of the spleen among sickle cell disease patients in a teaching hospital in Nigeria.
}

\author{
Charles Ugwoke Eze ${ }^{1}$, Godfrey Chukwudi Offordile ${ }^{2}$, Kennedy Kenechukwu Agwuna², Sunday Ocheni ${ }^{3}$, \\ Inoccent Uchechukwu Nwadike ${ }^{1}$, Bartholomew Friday Chukwu ${ }^{4}$
}

1. Medical Radiography and Radiological Sciences, University of Nigeria, Enugu Campus, Enugu State, Nigeria.

2. Radiation Medicine, University of Nigeria, Enugu Campus, Enugu State, Nigeria.

3. Haematology \& Immunology, University of Nigeria, Enugu Campus, Enugu State, Nigeria.

4. Paediatrics, University of Nigeria, Enugu Campus, Enugu State, Nigeria.

\begin{abstract}
Background: Regional variations in size and parenchyma echo-texture of the spleen among sickle cell disease (SCD) patients have been documented in various publications. The objectives of this study were to assess the size and parenchyma echo-texture of the spleen of SCD patients and ascertain the relationship of age, height and weight with the spleen sizes.

Methods: This was a cross sectional study involving 103 each of SCD and age matched control subjects. Aloka ST- 550 3500 ultrasound machine with 3.5 and $5 \mathrm{MHz}$ convex transducers was used to scan the subjects over a 15 months period (September, 2012 to November, 2013). The age, height and weight of each subject were recorded.

Results: The spleen sizes of SCD patients were generally larger than those of the controls $(p<0.05)$. Abnormal spleen parenchyma of varied appearances was found among the SCD subjects. There were negative correlations between mean spleen sizes and height, weight and age in SCD patients but positive correlations were found between them in the controls. Conclusion: Routine sonographic assessment of spleen size and echo-texture is useful in the management of SCD patients. Key words: sickle cell disease, sonography, spleen morphology, patient management, Nigerian population.

DOI: http://dx.doi.org/10.4314/ahs.v15i3.32

Cite: Eze CU, Offordile GC, Agwuna KK, Ocheni S, Nwadike IU, Chukwu BF. Sonographic evaluation of the spleen among sickle cell disease patients in a teaching hospital in Nigeria. Afri Health Sci. 2015;15(3):949-58. doi: http:/ / dx.doi.org/10.4314/ abs.v15i3.32
\end{abstract}

\section{Introduction}

Haemoglobinopathy is a genetic disorder including sickle cell disease (SCD) and thalassaemia. Sickle cell disease is a qualitative genetic disorder in which there is alteration in the normal globin chain, while thalassaemia refers to a quantitative haemoglobin disorder in which there is reduced or even absent synthesis of normal globin chains. ${ }^{1-4}$ Sickle cell disease is an autosomal recessive genetic disorder of the blood characterized by red blood cells (RBCs) that assume abnormal, rigid and sickle shapes. This condition stimulates high blood viscosity, low oxygen affinity in RBCs, vaso-occlusions especially the tiny blood vessels, ischaemias, acute pains, infarctions and fibrosis of dependant tissues. ${ }^{1,3,5}$ It is as-

\section{Corresponding author: \\ Charles Ugwoke Eze \\ University of Nigeria, Enugu Campus, \\ Medical Radiography and Radiological Sciences \\ Email: ugwoke.eze@unn.edu.ng/ \\ ezecharlesu@yahoo.com}

sociated with pathologic consequences of chronic and life-long illnesses. Patients with SCD often have different forms of sickle cell crises. ${ }^{1,4}$ Sickle cell disease is a common genetic condition that is globally wide-spread and particularly common among people from sub-Saharan Africa, India, Saudi Arabia, and Mediterranean countries. ${ }^{1}$

Each year about 300,000 infants are born with sickle cell disease globally, out of which about 200,000 cases occur in Africa, and 150,000 of these SCD children are born annually in Nigeria alone. ${ }^{4}$ About $5 \%$ of the world's population carry genes responsible for SCD. The frequency of sickle cell trait in West African countries like Ghana and Nigeria is $15 \%$ to $30 \% .{ }^{6}$ Sickle cell gene is common in Africa because the sickle cell trait confers some resistance to falciparum malaria infection during the critical period of early childhood. The frequency of the carrier state determines the prevalence of SCD at birth. ${ }^{6}$ Only the inheritance of a single abnormal gene - sickle cell trait - offers protection against malaria. Inheritance of two abnormal genes (sickle cell disease) confers no such protection. Hence, malaria is 
a major cause of ill-health and death in children with SCD. ${ }^{1,4,6}$

Sickle cell disease contributes the equivalent of $5 \%$ of under-five deaths on the African continent, more than $9 \%$ in West Africa, and up to $16 \%$ of under-five deaths in individual West African countries like Nigeria. ${ }^{4,6}$ Half of those with SCD usually die by the age of 5 years in sub-Saharan Africa from infections such as malaria, pneumococcal sepsis, and anaemia. ${ }^{4,6}$

Spleen is the most affected organ in SCD, because it receives the insults of the associated clinical conditions of this pathology earlier than the other vulnerable body organs such as the liver, gallbladder, kidneys and bone marrow. ${ }^{78}$ This is due to its peculiar anatomy and physiology - it has narrow blood vessels and filters the systemic blood..$^{7-9}$ There is a need to develop models of care appropriate to the management of sickle cell disease in sub-Saharan Africa which will be based on constant monitoring, early detection of crises, and early presentation to the specialist treatment centers. ${ }^{6}$ Early monitoring and detection are enhanced by ultrasonography of the spleen because the spleen responds to different pathologic states such as fever and sickle cell disease by dimensional and parenchyma changes. ${ }^{10,11}$ Regional variations in splenic size and spleen parenchyma echo-texture among sickle cell disease (SCD) patients exist in different publications. ${ }^{12-16}$ No such study has been documented in our locality.

This study was, therefore, aimed at assessing the size and parenchyma echo- texture of the spleen of SCD patients and the relationship of age, height and weight with the spleen size in a Nigerian population. The information from this study will add to the pool of knowledge on SCD and in the management of such patients in our center.

\section{Patients and methods}

This is a cross-sectional prospective study conducted over a 15 month period (September, 2012 to November, 2013) at the University of Nigeria Teaching Hospital (UNTH), Enugu. Ethical approval was obtained from the Hospital's Research and Health Ethics Committee, and informed consent was obtained from the SCD subjects and controls or their care-givers prior to the study.
Convenience sampling technique was used to recruit 103 stable SCD patients from sickle cell disease clinic of UNTH, Enugu and 103 healthy age matched control subjects. The controls were recruited from apparently healthy, normal genotype, patients on referrals from general outpatient department to radiation medicine department of UNTH, Enugu for routine abdominal sonography. The subjects were aged 2-58 years.

\section{Inclusion criteria}

The study subjects (SCD and control subjects) were confirmed to have either HbSS/HbSC or HbAA genotype, were negative for malaria and typhoid disease, with no history of surgical splenectomy nor any other surgery in the last one year. The controls had no history of blood transfusion and no chronic or acute ailment of recurrent nature; while SCD subjects had no crisis in the past three months prior to the study.

\section{Exclusion criteria}

Pregnant and breast feeding mothers, and female subjects that had abortion in the previous six months were excluded from the study.

\section{Equipment}

Aloka ST-550 - 3500 (Hannover, Germany) real time ultrasound machine with $3.5 \mathrm{MHz}$ and $5 \mathrm{MHz}$ curvilinear probes was used to scan the study groups. The ultrasound machine was validated for quality performance by the departmental medical physicist prior to the measurements. Using the available freeze-frame capability, all the sonographic measurements were made with curvilinear probes using the electronic calipers.

Demographic data was collected on each participant at the time of their pre-participation physical examination. This information included age, sex, height and body weight. The age of each subject was obtained from his / her hospital birth certificate. Anthropometric measurements were obtained on the participants wearing light weight street clothes without shoes. Weight was measured on a calibrated portable Salter scale (BR 9011; Hana Co. Ltd, China) to the nearest $0.1 \mathrm{~kg}$. Height was measured with a metal tape measure to the nearest $0.5 \mathrm{~cm}$ with the participants standing upright with the head in the Frankfurt position.

\section{Scanning technique}

The technique of right lateral decubitus position in the 
coronal plane was adopted for this study because of superior advantage of obtaining easily the longest dimension of the spleen and reproducibility of measurement ${ }^{14}$. Longitudinal size measurement was performed between the most superomedial and the most inferolateral points of the spleen. The transverse dimension was measured between the hilum and the most superolateral margin of the spleen. The choice of probe depends on the age and physique of the subjects. For instance, the 3.5 $\mathrm{MHz}$ probe was predominantly used for imaging subjects aged 15 years and above and for overweight children from 12 to 14 years of age whereas the $5 \mathrm{MHz}$ probe was predominantly used for imaging slim children below 15 years of age and very thin adult SCD patients.

A subgroup of twenty five participants underwent three ultrasound scans of the spleen done two days apart by three different sonographers to determine intra- and inter rater reliability of spleen size measurements (pilot study). The sonographers had 12 years of experience in abdominal sonography. One of these sonographers did all the scanning for the main study. Spleen sizes were measured three times, and the mean values were recorded. The measurement of spleen dimensions was made during deep inspiration.

\section{Statistical analysis}

Difference of continuous variables between two independent groups was assessed with the Student's t-test while more than two groups were assessed with analysis of variance (ANOVA). Intra class correlation coefficients (ICCS) were calculated to assess inter- and intra rater reliability for ultrasound measurement of the spleen, using SPSS statistical package version 10.14 (SPSS Chicago, Illinois, USA). Statistical significance was considered at $p<0.05$. Descriptive statistical methods were used when appropriate.

\section{Results}

Table 1 shows inter- and intra-variability coefficients in the measurement of spleen length as 0.83 and 0.94 respectively, while those of spleen width were 0.52 and 0.76 respectively.

Table 1: Intra- and Inter-ratter reliability of Sonographic measurements of spleen size.

\begin{tabular}{|c|c|c|c|c|c|}
\hline \multirow[t]{2}{*}{ Observer } & \multicolumn{5}{|c|}{ Intra- and Inter-Ratter Reliability (Intra class correlation coefficient at 95\% confidence interva } \\
\hline & Variables & $\mathrm{F}$ & lower bound & upper bound & Intra-class correlation values \\
\hline \multicolumn{6}{|l|}{ Intra-observer, } \\
\hline \multirow[t]{2}{*}{ Sonographer 1} & Length & 25 & 0.88 & 0.97 & $\operatorname{ICC}(3,2,1)=0.94$ \\
\hline & Width & 25 & 0.54 & 0.89 & $\operatorname{ICC}(3,2,1)=0.76$ \\
\hline \multicolumn{6}{|l|}{ Intra-observer, } \\
\hline \multirow[t]{2}{*}{ Sonographer 2} & Length & 25 & 0.86 & 0.95 & $\operatorname{ICC}(3,2,1)=0.92$ \\
\hline & Width & 25 & 0.52 & 0.87 & $\operatorname{ICC}(3,2,1)=0.74$ \\
\hline \multicolumn{6}{|l|}{ Intra-observer, } \\
\hline \multirow[t]{2}{*}{ Sonographer 3} & Length & 25 & 0.89 & 0.98 & $\operatorname{ICC}(3,2,1)=0.95$ \\
\hline & Width & 25 & 0.55 & 0.90 & $\operatorname{ICC}(3,2,1)=0.77$ \\
\hline \multicolumn{6}{|l|}{ Inter-observer, } \\
\hline \multirow[t]{2}{*}{ All Sonographers } & Length & 25 & 0.70 & 0.91 & $\operatorname{ICC}(3,2,1)=0.83$ \\
\hline & Width & 25 & 0.28 & 0.73 & $\operatorname{ICC}(3,2,1)=0.52$ \\
\hline$=$ Frequency: ICC & $=$ Intra $\mathrm{cl}$ & corr & ation coeffic & $t:$ & \\
\hline
\end{tabular}


Table 2 shows matched demographic features of all the study subjects.

Table 2: Demographic characteristics of the subjects (HbSS, HbSC \& HbAA)

\begin{tabular}{|c|c|c|c|c|c|}
\hline \multirow{2}{*}{ Variables } & & \multicolumn{2}{|c|}{ Stable SCD Patients } & \multicolumn{2}{|c|}{ Healthy HbAA Controls } \\
\hline & & Frequency & $\%$ & Frequency & $\%$ \\
\hline \multirow[t]{8}{*}{ AG (years) } & $2-6$ & 17 & 16.50 & 17 & 16.50 \\
\hline & $7-11$ & 20 & 19.42 & 19 & 18.45 \\
\hline & $12-16$ & 13 & 12.60 & 14 & 13.59 \\
\hline & $17-21$ & 13 & 12.60 & 13 & 12.60 \\
\hline & $22-26$ & 19 & 18.45 & 18 & 17.48 \\
\hline & $27-31$ & 8 & 7.80 & 8 & 7.80 \\
\hline & 32 and above & 13 & 12.60 & 14 & 13.59 \\
\hline & Total & 103 & 100.00 & 103 & 100.00 \\
\hline \multirow[t]{3}{*}{ Sex } & Male & 48 & 46.60 & 56 & 54.40 \\
\hline & Female & 55 & 53.40 & 47 & 45.60 \\
\hline & Total & 103 & 100.00 & 103 & 100.00 \\
\hline \multirow[t]{3}{*}{ MS } & Single & 97 & 94.20 & 94 & 91.30 \\
\hline & Married & 6 & 5.80 & 9 & 8.70 \\
\hline & Total & 103 & 100.00 & 103 & 100.00 \\
\hline \multirow[t]{4}{*}{ Gt. } & $\mathrm{HbSC}$ & 2 & 1.90 & - & - \\
\hline & $\mathrm{HbSS}$ & 101 & 98.10 & - & - \\
\hline & $\mathrm{HbAA}$ & - & - & 103 & 100.00 \\
\hline & Total & 103 & 100.00 & 103 & 100.00 \\
\hline
\end{tabular}

AG (years) = Age groups in years: $\mathrm{Gt}=$ Genotype $: \mathrm{MS}=$ Marital Status

$\mathrm{HbSC}=$ Compound Heterozygous Sickle Haemoglobin SC:

$\mathrm{HbSS}=$ Homozygous Sickle Haemoglobin SS or Sickle Cell Anaemia:

$\mathrm{HbAA}=$ Homozygous Haemoglobin AA or the Normal Genotype:SCD = Sickle Cell Disease.

Table 3 shows the incremental variation of spleen sizes across the age groups in the control subjects, and an undulating variation in spleen sizes in the SCD subjects. Generally, the mean spleen length in SCD subjects was
$97.67 \pm 39.61 \mathrm{~mm}$, while that of the control subjects was $80.84 \pm 16.89 \mathrm{~mm}$. Mean spleen width in SCD subjects was $47.28 \pm 20.68 \mathrm{~mm}$, and that of the control subjects was $39.38 \pm 9.39 \mathrm{~mm}$. 
Table 3: Mean spleen sizes of the sickle cell disease patients by age compared with those of the controls.

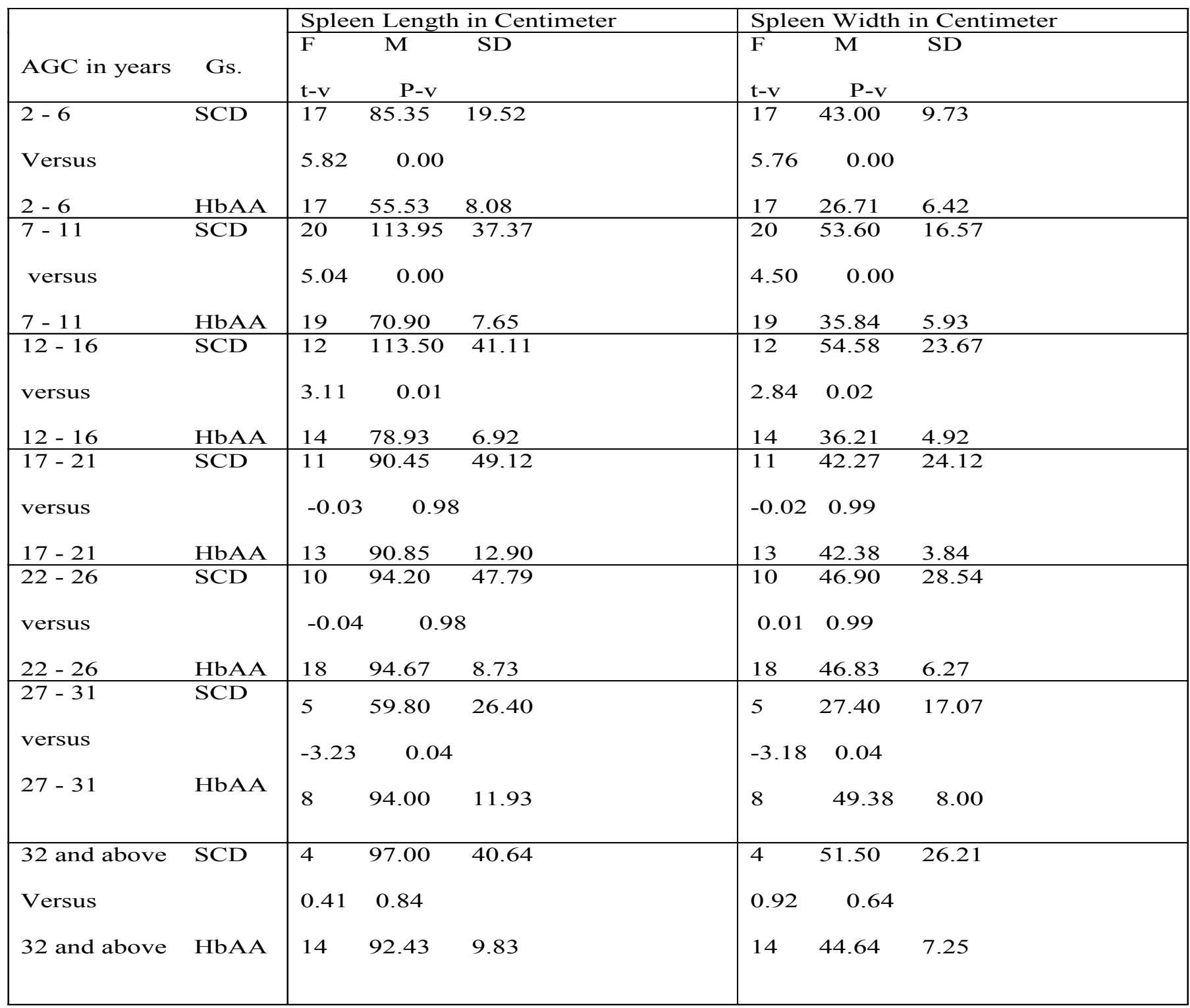

$\mathrm{AGC}=$ Age groups being compared. $\mathrm{Gs}=$ Genotype status. $\mathrm{F}=$ Frequency

$\mathrm{M}=$ Mean: $\mathrm{SD}=$ Standard Deviation: $\mathrm{t}-\mathrm{v}=\mathrm{t}$-value: $\mathrm{P}-\mathrm{v}=\mathrm{P}$-value

$\mathrm{HbAA}=$ Homozygous Haemoglobin AA or the Normal Genotype

$\mathrm{SCD}=$ Sickle Cell Disease

Table 4 shows negative correlation between mean spleen sizes and age $(r=-0.13)$, height $(r=-0.17)$, and weight $(r=-0.06)$ among SCD subjects, whereas there was positive correlation between mean spleen sizes and age $(r=0.63)$, height $(r=0.85)$, and weight $(r=0.83)$ in the control subjects. There were no variations of spleen sizes with sex in either group of subjects $(\mathrm{P}>0.05)$. 
Table 4: Comparison of the effects of age, height, and weight on the spleen sizes of the stable sickle cell disease patients and healthy control subjects.

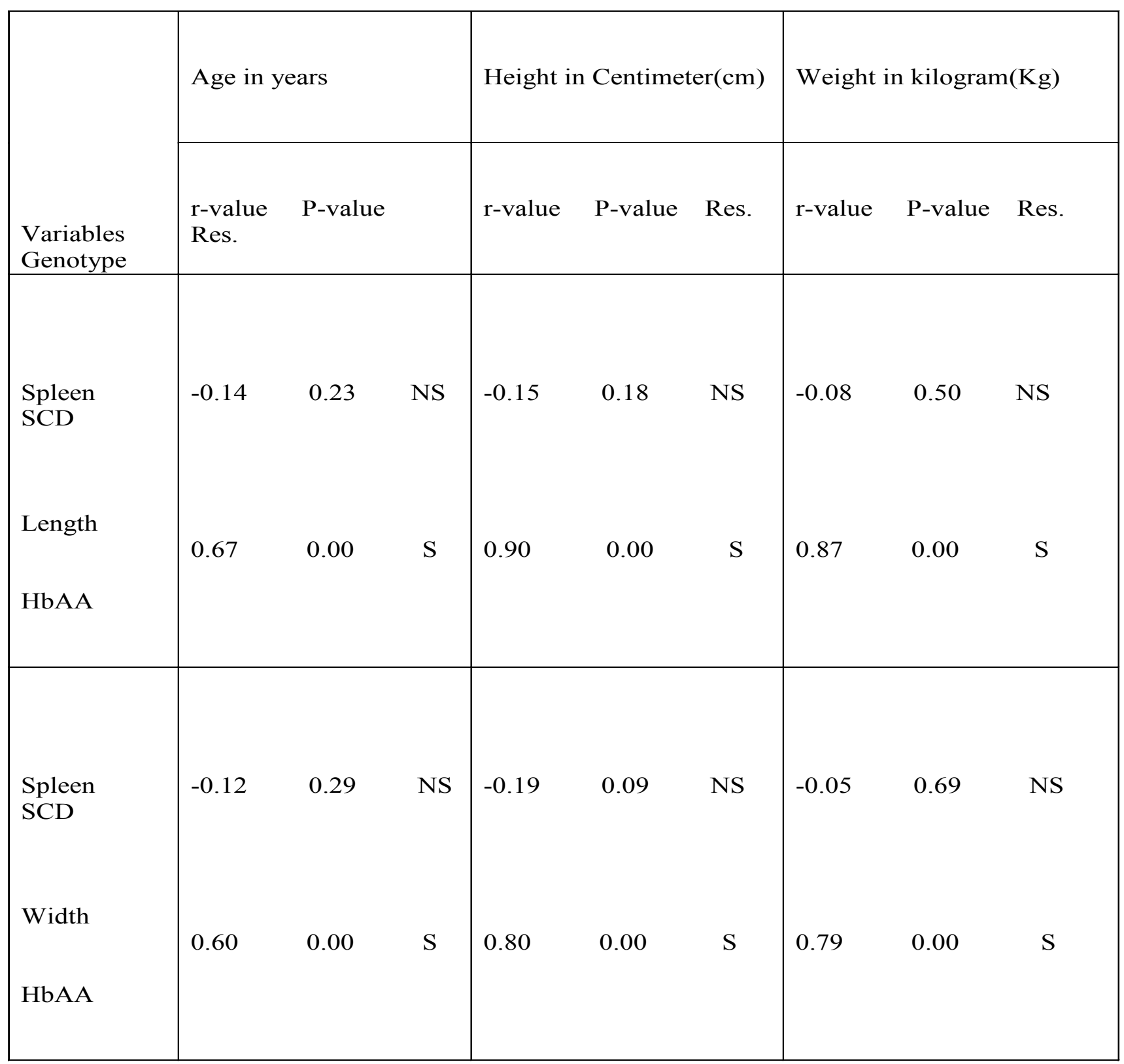

Res.= Results.: NS= Not Significant.: $\mathrm{S}=$ Significant.

$\mathrm{HbAA}=$ Homozygous Haemoglobin AA or the Normal Genotype.

$\mathrm{SCD}=$ Sickle Cell Disease.

Table 5 shows $8.74 \%$ normal spleen parenchyma, 21.36 $\%$ fibrotic scar littered parenchyma, 2.91\% infarction/ abscess littered parenchyma, $4.85 \%$ calcification littered parenchyma, $19.42 \%$ fine hyper echoic parenchyma and $19.42 \%$ coarse hyper echoic parenchyma among the SCD subjects, while normal spleen parenchyma was visualized in all the control subjects. 
Table 5: Characterization of the spleen parenchymal echo texture in the sickle cell disease patients.

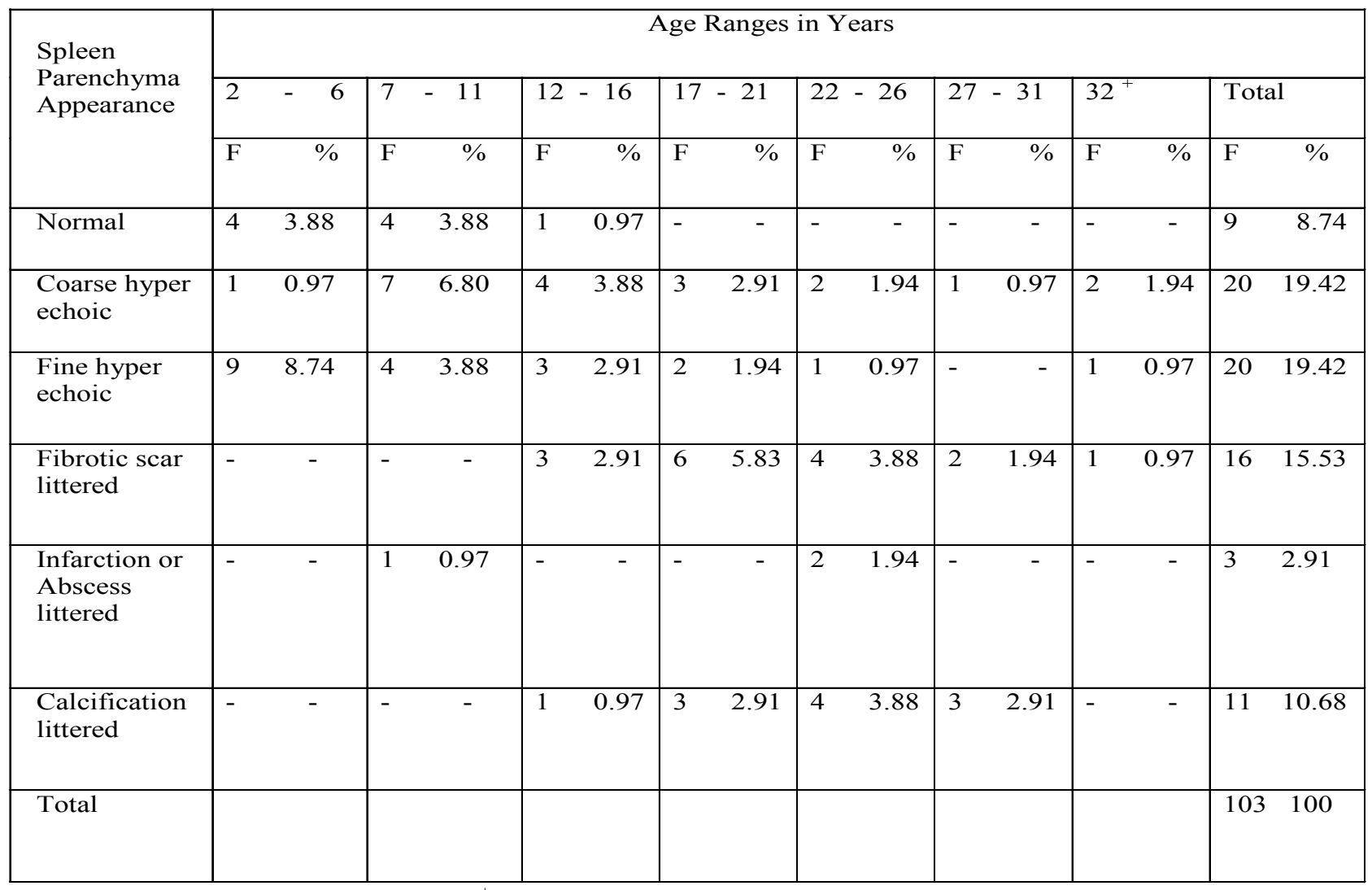

$\mathrm{F}=$ Frequency. : $\%=$ Percentage. $: 32^{+}=32$ years and above.

Normal $=$ Normal Spleen Parenchyma Echo Texture. : Auto-Splenectomy $=$ Absence of Spleen

Figure 1 shows the trends of the spleen sizes (spleen length and spleen width) of the SCD subjects and those of the controls compared.

Figure 1: Comparison of the trends of the overall spleen sizes (spleen length and spleen width) of sickle cell disease subjects with those of the control subjects.

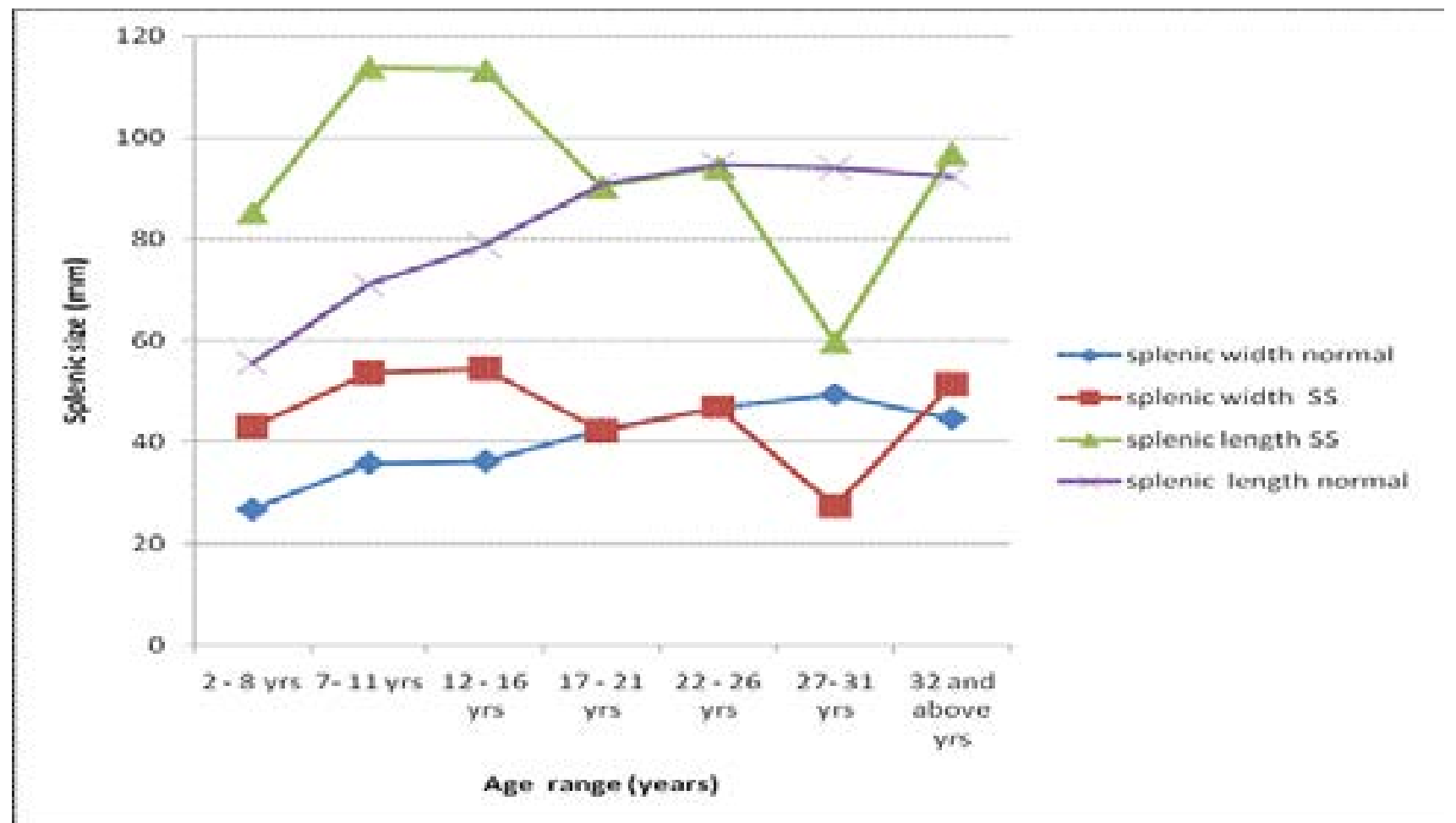




\section{Discussion}

Variations in splenic size and parenchyma echo-texture of sickle cell disease (SCD) patients exist in the literatures reviewed due to differences in race, haplotype, ethnicity and clime. ${ }^{12,13,15,17,18}$ Consequently, some authors opined the need to establish population specific normal abdominal organ morphology in different climes and ethnicities. ${ }^{6,11,14}$ Measurement of the spleen by a competent sonographer using a high quality ultrasound machine and proper technique is reliable. This is shown by the low inter- and intra-observer errors of the pilot study $(\mathrm{P}>0.05)$. This finding agrees with the result of a previous study. ${ }^{14}$

In this study, the spleen of SCD subjects generally had undulating variations in size increasing rapidly from 2 years of age to the childhood/adulthood transitional age of 18 years. Beyond 18 years, there was a mixture of sharp reduction and increase in spleen size in an undulating form up to the age of 58 years. Maximum numbers of shrunken spleen and auto-splenectomy were recorded between 18 years and 33 years age in this study. This implies that, in our locality, the spleen of patients with SCD increases rapidly in size from early age and peaks at 18 years, and generally declines sharply to either a shrunken state or auto-splenectomy. This trend contradicts the findings of previous authors ${ }^{12,13,15-}$ ${ }^{17}$ probably because of differences in study protocol, clime and haplotype. It can also be related to high malaria endemicity and frequent bacterial infections that may cause hypertrophy and hyperplasia of the spleen in our environment. However, the trend of spleen sizes across the age groups in the control subjects is incremental or gradual in form from early age with a peak at 30 years in the present study. This concurs with the finding of Okoye et $\mathrm{al}^{11}$ in a similar population.

The mean spleen sizes of SCD patients were generally larger than those of the controls $(\mathrm{P}<0.05)$, specifically in children (age range $2-17$ years). This could be due to low body immunity in this age range with resultant high susceptibility of SCD subjects to the acute complications of sickle cell condition. This result agrees with the findings of previous works ${ }^{12,16,21}$ possibly because of similarity in study protocol, but disagrees with the work of Babadoko et $\mathrm{al}^{13}$ in Zaria, Nigeria.

Many authors, ${ }^{13,14,18,20-24}$ are of the opinion that a simple single measurement of spleen length is an accurate estimate of spleen size as it correlates strongly with the actual spleen dimensions (spleen length, volume and weight) at autopsy. Compared with spleen width in the present study, the spleen length showed the highest correlation with the body parameters. There is negative correlation between spleen length and age $(\mathrm{P}=0.23 ; \mathrm{r}$ $=-0.14)$, height $(\mathrm{P}=0.18 ; \mathrm{r}=-0.15)$, and weight $(\mathrm{P}=$ $0.50 ; \mathrm{r}=-0.08)$ among SCD subjects. This is consistent with the findings of other previous authors. ${ }^{18,20}$ However, this contradicts the findings of significant correlation between age and spleen sizes by other researchers ${ }^{16,17,21}$ which could be as a result of differences in ethnicity, clime and haplotype. There is positive correlation between mean spleen sizes and age $(\mathrm{P}=0.00, \mathrm{r}=0.67)$, height $(\mathrm{P}=0.00, \mathrm{r}=0.90)$, and weight $(\mathrm{P}=0.00, \mathrm{r}=$ $0.87)$ in the control subjects. These findings are consistent with the findings of other scholars. . $^{11,14,18,21,23-25}$

In the present study, auto-splenectomy was detected in $23.30 \%$ of SCD subjects, while shrunken spleen was found in $10.86 \%$ of the SCD subjects. These are statistically smaller $(\mathrm{P}<0.05)$ than those of other previous works $^{13,26-28}$ but are significantly larger $(\mathrm{P}<0.05)$ than those of other authors. ${ }^{15,17}$ However, they concur with the findings of Awotua-Efebo et $\mathrm{al}^{12}$ in children population in Port Harcourt, Nigeria. Interestingly, our study included more paediatric subjects. Mild splenomegaly, moderate splenomegaly and massive splenomegaly were seen in $4.85 \%, 12.62 \%$ and $15.53 \%$ of the SCD subjects respectively in the current study. The threshold for mild splenomegaly is defined at one standard deviation (SD) above the average spleen size in the healthy population while the massive splenomegaly threshold is defined at two SD above the average spleen size in the healthy population. ${ }^{29}$ Moderate splenomegaly values are values between the upper limit and lower limits of mild and massive splenomegaly respectively as defined above. Generally, a total of $33.01 \%$ cases of splenomegaly were found in the present study. They are statistically larger $(\mathrm{P}<0.05)$ than those recorded by other related works. ${ }^{12,13,17,22,27}$ This may be because the present study included more paediatric patients. However, the splenomegaly cases in the present study are significantly lower $(\mathrm{P}<0.05)$ than the findings of other authors in an Indian ${ }^{15}$ and Greek ${ }^{28}$ populations.

A significant number of SCD subjects studied in this work had their spleen persisting into adult ages with consequent anomalous spleen parenchyma. Thus, we found $8.74 \%$ normal parenchyma, $19.42 \%$ coarse hyper echoic parenchyma, and $19.42 \%$ fine hyper echoic 
parenchyma in the SCD subjects. Others are 15.53\% fibrotic scar littered parenchyma, 2.91\% infarction/abscess littered parenchyma and $10.68 \%$ calcification littered parenchyma. Splenic calcifications in the current study were also both punctuate and amorphous among the SCD subjects.

Splenic infarction and abscess are difficult to differentiate by sonography alone; hence, they were characterized together as infarction/abscess littered parenchyma in the present study. The frequency of infarction/abscess littered parenchyma in the present study is too small relative to the findings of Mohanty et $a{ }^{15}$ probably because they studied SCD subjects in crisis state while the present study was on stable SCD subjects. The incidence of calcification littered parenchyma in this study concurs with the findings of others. ${ }^{15}$ This could be as a result of similarity in the age range of SCD subjects studied. The findings of the present study regarding infarction/abscess and calcification littered parenchyma significantly differed from a previous report in a Turkish population. ${ }^{22}$

\section{Limitations of the study}

Illiteracy and ignorance of most sickle cell disease patients and their guardians affected the data collection. A lot of time was spent explaining the nature and essence of this study to most of the SCD patients and their guardians before they gave their consent to participate. The study was of limited size and conducted at only 1 site. The subjective differences in the parenchyma echo-texture classification were not determined in this study.

\section{Conclusion}

The results of this study suggest inclusion of routine sonographic study of the spleen size and parenchyma echo-texture in the management of SCD patients.

\section{Recommendations}

1. Abdominal ultrasound investigation may be used to detect splenic infarction or splenic abscess, based on the size of the spleen and the splenic parenchyma echo-texture, in the sickle cell disease patients.

2. Routine abdominal sonographic examination should be made part of the clinical care given to all sickle cell disease patients.

Authors' contributions: CUE, GCO and IUN conceived the study; GCO, CUE, KKA, SO and BFC de- signed the study protocol; SO, BFC and KKA carried out the clinical assessment; CUE, KKA, GCO and IUN carried out the sonographic study; SO and BFC carried out the laboratory work; GCO, CUE and IUN carried out the analysis and interpretation of data; CUE and GCO drafted the manuscript; SO, BFC, KKA and IUN critically revised the manuscript for intellectual content. All authors read and approved the final manuscript. CUE and GCO are guarantors of the paper.

\section{Competing interests:}

None declared.

\section{Ethical approval:}

The study protocol number (NHREC/05/01/2008B - FWA00002458 -IRB00002323) entitled 'Sonographic assessment of the sizes and appearance of the spleen among sickle cell disease patients in university of $\mathrm{Ni}$ geria Teaching Hospital, Ituk/Ozalla, Enugu', was reviewed and approved by the University of Nigeria Health Research Ethics Committee (ref no: UNTH/ CSA/329/vol.5) in compliance with all Federal regulations governing the protection of human subjects.

\section{Acknowledgements:}

Our profound gratitude goes to Mazi Onyimba Eze, Mr. Aneke JC (Uncle Jimmy), Mrs Clara KE, Dr. Ogbuehi JA, and all the staff of sickle-cell disease clinics and Radiation Medicine Department of UNTH, Ituku-Ozalla, Enugu for their contributions during data collection.

\section{References}

1. Desai DV, Hiren D. Sickle cell disease: History and origin. The internet journal of haematology 2004; 2: 47.

2. Dorland WAN. Spleen. Dorland's pocket medical dictionary. 28th ed. Philadelphia: Elsevier Saunders 2009; 780 .

3. Lanzkowsky P. Sickle cell anaemia. Manual of paediatric haematology. 5th ed. Ohio: Academic press 2011; pp $200-31$.

4. Oguejiofor GC. Fundamentals of sickle cell disease. First edition. Enugu . Uchenna press; 1999: pp 1 - 14.

5. Aldrich TK, Nagel RL. Pulmonary complications of sickle cell disease. In: Reynolds HY, Bone RC, Dantzker DR et al.(eds). Pulmonary and critical care medicine. 6th ed. St. Louis: Mosby 1998; pp $1-10$.

6. Fifty-Ninth World Health Assembly. Sickle cell anaemia - Report by the secretariat. World Health Organization 2006. A59/9 : Provisional Agenda Item 11.4 : 1 - 5 . 
7. de Montalembert M. Management of sickle disease. British Medical Journal 2008; 337: a1397.

8. Stuart MJ, Nagel RL. Sickle cell disease. Lancet 2004; 364 (9442): 1343 - 60.

9. Steinberg MH, Barton F, Castro O. Effects of hydroxyurea on mortality and morbidity in adult Sickle cell anaemia : Risks and benefits up to 9 years of treatment. Journal of the American Medical Association 2003; (13): $1645-51$.

10. Curry RA, Tempkin BB. The Spleen. Ultrasonography : An Introduction to Normal Structure and Functional Anatomy. 1st ed. London: Saunders WB 1995; 9:136 - PubMed ; 43.

11. Okoye IJ, Agwu KK, Ochie K. Sonographic splenic sizes in normal adult Nigerian population. West African Journal of Radiology 2005; 12(1): 37 -47.

12. Awotua-Efebo O, Alikor EAD, Nkanginieme KEO. Malaria parasite density and splenic status by ultrasonography in stable sickle cell anaemia (HbSS) children. Nigerian Journal of Medicine 2004; 13 (1): 23 - 27.

13. Babadoko AA, Ibinaye PO, Hassan A et al. Autosplenectomy of sickle cell disease in Zaria, Nigeria: an ultrasonographic assessment. Oman Medical Journal 2012; 27(2): 121 - 126.

14. Eze CU, Agwu KK, Ezeasor DN et al. Sonographic biometry of spleen among school age children in Nsukka, Southeast, Nigeria. African Health Sciences 2013; 13 (2): $384-395$.

15. Mohanty J, Narayan JVS, Bhagat S, Panda BB, Satpathi G, Saha N. Sonological evaluation of abdominal organs in sickle cell crisis in Western Orissa. Indian Journal of Radiology and Imaging 2004; 14: 247 - 251.

16. Olatunji AA, Olatunji PO. Splenic size determination in sickle cell anaemia: an ultrasonographic study. East African Medical Journal 2001; 78 (7): 366 - 369.

17. Ahmed HA, Prabhakar B, Ali A, Ibrahim A. Sonographic assessment of spleen size in Saudi patients with sickle cell disease. Annals of Saudi Medicine 1998; 18 (3): $217-219$.

18. Udoaka AI, Enyi C, Agi CE. Sonological evaluation of the liver, spleen and the kidneys in an adult Southern Nigerian population. Asian Journal of Medical Sciences 2013; 5(2): 33 - 38.
19. Hofer M. Spleen. Ultrasound teaching manual: the basics of performing and interpreting ultrasound scans. 2nd ed. New York: George Thiene 1999; 6: 47 - 9.

20. Ogbeide E, Marchie TT. Determination of normal dimension of the spleen by ultrasound in an endemic tropical environment. Nigerian Medical Journal 2011; 52(3): $198-203$.

21. Nita AT, Ambiye MV, Vilpa AT, Himanshu AJ. U1trasonic measurement of splenic size of normals and comparison with various medical disorders involving spleen in paediatric Indian population. National Journal of Integrated Research in Medicine 2012; 3(4): 65 - 75.

22. Ali B, Sinem K, Ozlem S et al. Prevalence of abdominal ultrasonographic abnormalities in patients with sickle cell disease. Special Journal of the Turkish Society of Radiology 2008; 14 (3): 133 - 137.

23. Audrey LS, David MD, Mark AK. Sonographic evaluation of spleen size in tall healthy athletes. American Journal of Roentgenology 2005; 184: 45 - 49.

24. Stylianos DM, Ioannis GV, Amalia MT. Spleen length in childhood with US: Normal values based on age, sex, and somatometric parameters. Radiology 2004; 231(1): $129-134$.

25. Bhavna D, Suvasini S, Devendra M, Reema K, Ravindra MP, Shailendra A. Normal values of liver and spleen size by ultrasonography in Indian children. Indian Pediatrics 2010; 47: 487 - 494.

26. Ahmed HA. Indications and complications of splenectomy for children with sickle cell disease. Saudi Arabia Journal of Pediatric Surgery 2006; 41:1909-15.

27. Bakhieta IA. Abdominal sonographic findings in children with sickle cell anaemia. Journal of Diagnostic Medical Sonography 2010; 26 (6): 281 - 285.

28. Marina GP, Antonios C K, Irene GP, Damianos G M, Theano PG, Anna M et al. Abdominal ultrasonographic findings in patients with sickle cell anaemia and thalassaemia intermedia. Pediatric Radiology of Greece 2003; 33 (8): 515 - 521.

29. Linguraru MG, Sandberg JK, Jones EC, Summers RM. Assessing splenomegaly: Automated volumetric analysis of the spleen. Academic Radiology 2013; 20 (6): $675-684$. 